\title{
Integrated quantitative first-pass cardiac perfusion MRI protocol
}

\author{
Elodie Breton*, Daniel Kim, Sohae Chung, Leon Axel \\ From 2011 SCMR/Euro CMR Joint Scientific Sessions \\ Nice, France. 3-6 February 2011
}

\section{Introduction}

The proposed contrast-enhanced first-pass perfusion cardiovascular MR (CMR) protocol integrates some recent technical MRI advances towards quantitative analysis of perfusion CMR images: fast multi-slice pulse sequence [1], robust saturation pulse [2], accurate dedicated AIF imaging [3], signal-to-concentration modeling [4], and higher SNR at 3T.

\section{Purpose}

To evaluate an integrated first-pass perfusion cardiovascular MR (CMR) protocol designed to determine absolute contrast-agent concentrations in blood and tissues.

\section{Methods}

A multi-slice saturation recovery (SR) pulse sequence with sequential SR time delays (TD) after a non-selective saturation pulse [2] was implemented at 3T (Fig. 1). The rationale for this acquisition scheme was to acquire a dedicated arterial input function (AIF) image with a short TD $(50 \mathrm{~ms})$ in the aortic root and short-axis myocardial images with longer TD values $(\sim 150-400 \mathrm{~ms})$, to allow for the different amounts of $\mathrm{T}_{1}$ shortening expected in blood and wall. First-pass perfusion CMR was performed in 7 volunteers $(0.05 \mathrm{mmol} / \mathrm{kg}$, GdDTPA). A signal-to-concentration model was applied to calculate Gd-DTPA concentrations in blood and tissues $[4,5]$. A proton density-weighted ( $\mathrm{PDw}$ ) image was acquired in the first heartbeat, without the saturation pulse, in order to normalize the image signal, and obtain a theoretical signal-to- $\mathrm{T}_{1}$ relationship based on Bloch equation in the center of k-space. Gd-DTPA concentrations were calculated assuming: fast water exchange condition [6], longitudinal relaxivity $\mathrm{r}_{1}=3.8 \mathrm{~L} \cdot \mathrm{mmol}^{-1} \cdot \mathrm{s}^{-1}$ [7], and baseline $T_{1}$ measured with a multi-point SR fit.

NYU Langone Medical Center, New York, NY, USA

TurboFLASH imaging parameters included: FOV= $350 \mathrm{~mm} \times 315 \mathrm{~mm}$, slice thickness $=8 \mathrm{~mm}$, matrix $=160 \times 144$, in-plane resolution $=2.2 \mathrm{~mm} \times 2.2 \mathrm{~mm}, \mathrm{TE} / \mathrm{TR}=1.2 / 2.4 \mathrm{~ms}$, flip angle $10^{\circ}$, temporal resolution $=114 \mathrm{~ms}$, tSENSEx3, centric $\mathrm{k}$-space trajectory, and receiver bandwidth= $1008 \mathrm{~Hz} /$ pix. Total image acquisition time was $523 \mathrm{~ms}$ for the acquisition of 4 slices, namely aortic root and SA base, mid, and apex levels, with respective TD values 50-164-278-393ms. Contours for the blood and left ventricle were drawn manually, and the myocardium was divided into 6 (base-mid) or 4 (apex) standard segments.

\section{Results}

Representative images at peak contrast in blood and myocardium are shown Fig. 2, along with representative AIF and myocardial segment time-responses. The peak

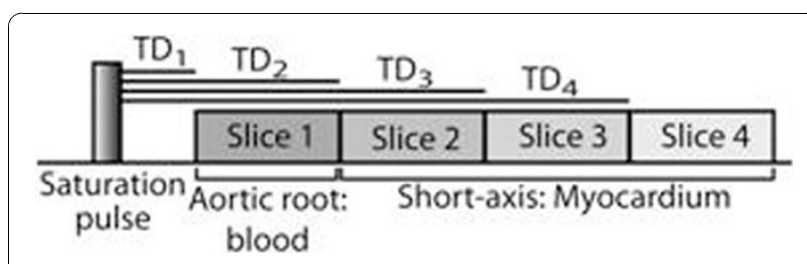

Figure 1 Schematic diagram of the mulit-slice with sequential TD first-pass perfusion CMR pulse sequence.

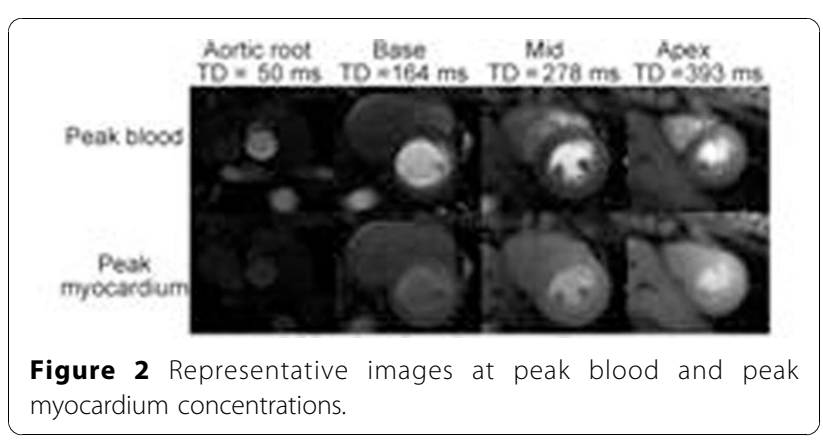




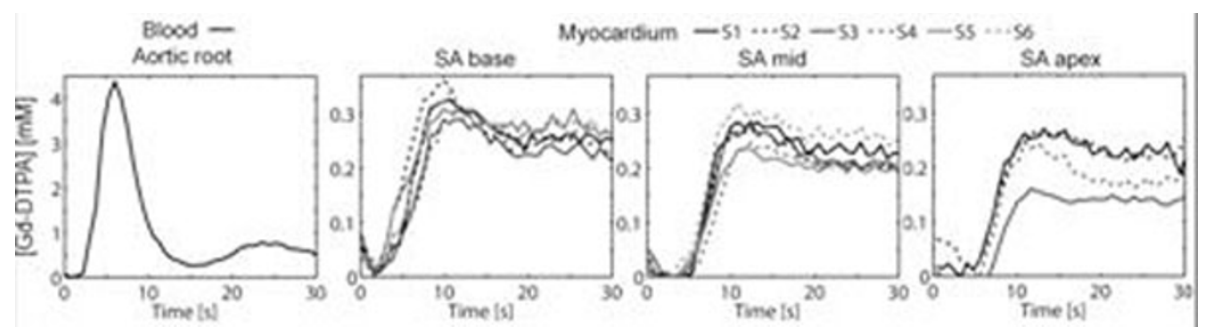

Figure 3 Representative [Gd-DTPA] times-curves in blood in the aortic root and in 6 cardiac segments in cardiac short-axis images.

blood signal was not clipped in the short $\mathrm{TD}=50 \mathrm{~ms}$ AIF images. Normalized signal in the myocardium increased along with TD; however similar [Gd-DTPA] were measured in all 3 short-axis images. First-pass perfusion peak Gd-DTPA concentrations were $3.95 \pm 0.080,0.26$ $\pm 0.07 \mathrm{mM}$ in the blood and myocardium, respectively.

\section{Conclusions}

The proposed integrated first-pass perfusion CMR protocol at 3T produced AIF and myocardial wall GdDTPA concentrations consistent with previously published results. Future work includes evaluation of the integrated protocol in cardiac patients.

Published: 2 February 2011

\section{References}

1. Nagel $E$, et al: Circulation 2003, 108:432-437.

2. Kim D, et al: Magn Reson Med 2008, 62:1368-1378.

3. Kim D, Axel LJ: Magn Reson Imaging 2006, 23:81-86.

4. Cernicau A, Axel L: Acad Radiol 2006, 13:686-693.

5. Breton E, et al: SCMR 2010.

6. Dobahue KM, et al: J Magn Reson Imaging 1997, 7:102-110.

7. Rohrer M, et al: invest Radiol 2005, 40:715-724.

doi:10.1186/1532-429X-13-S1-P60

Cite this article as: Breton et al:: Integrated quantitative first-pass cardiac perfusion MRI protocol. Journal of Cardiovascular Magnetic

Resonance 2011 13(Suppl 1):P60.
Submit your next manuscript to BioMed Central and take full advantage of:

- Convenient online submission

- Thorough peer review

- No space constraints or color figure charges

- Immediate publication on acceptance

- Inclusion in PubMed, CAS, Scopus and Google Scholar

- Research which is freely available for redistribution

Submit your manuscript at www.biomedcentral.com/submit 